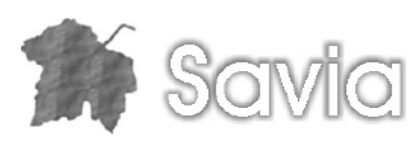

Análisis

\title{
El Desarrollo Social: sus orígenes y definición conceptual
}

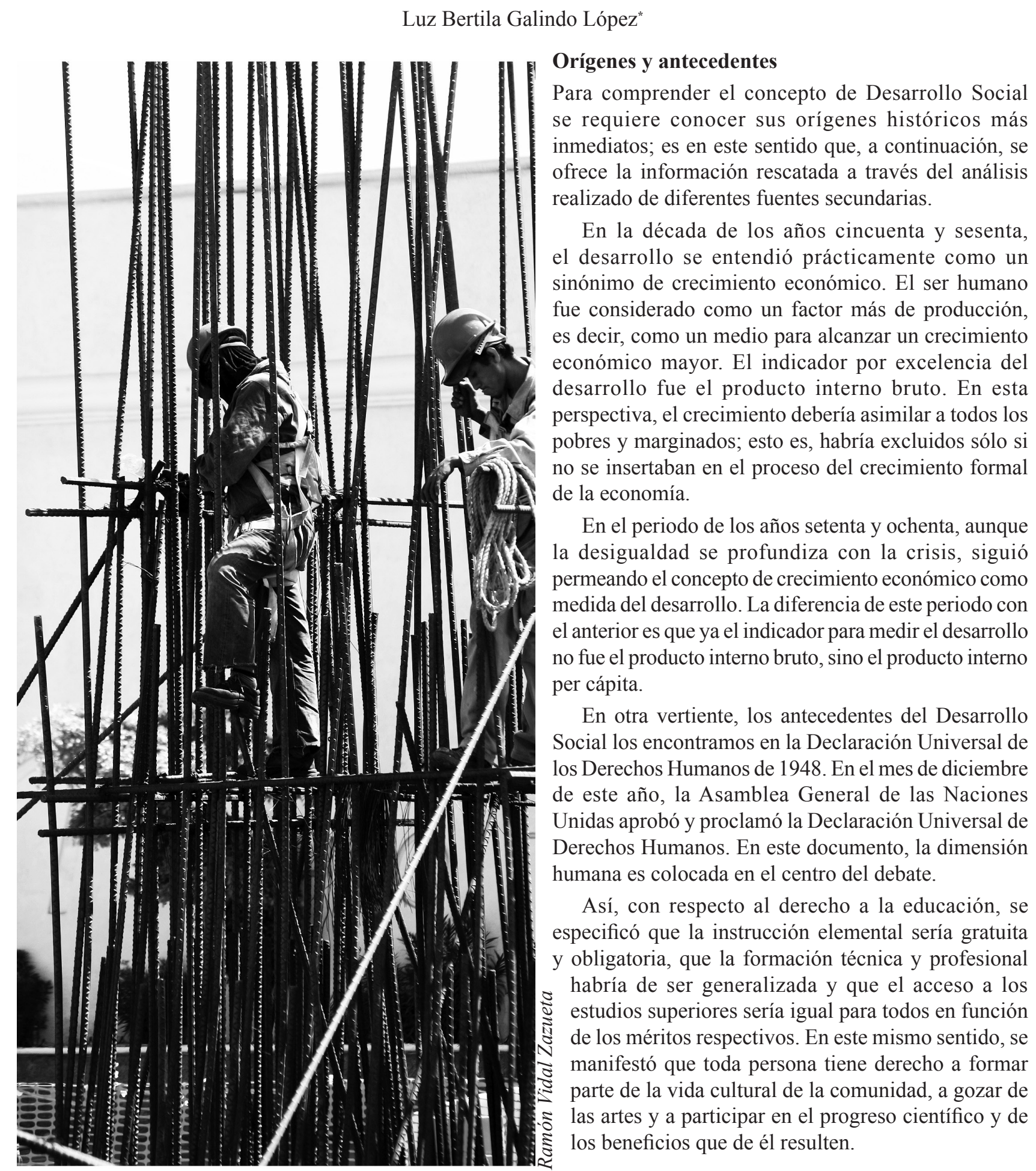

Maestría en Política y Gestión del Desarrollo Social. Universidad de Sonora. Igalindo@sociales.uson.mx 
Igualmente, en la Declaración de 1948 se incluyó el derecho de las personas a acceder al trabajo bajo condiciones equitativas y satisfactorias. De éste se derivaron los siguientes: derecho a un nivel de vida adecuado que le asegure al trabajador y a su familia la alimentación, el vestido, la vivienda, la asistencia médica y los servicios sociales necesarios; protección contra el desempleo, derecho a los seguros en caso de enfermedad, invalidez, viudez, vejez u otros casos de pérdida de sus medios de subsistencia por circunstancias independientes de su voluntad.

Otros derechos son los de carácter político y de equidad de género. En la declaración se hizo hincapié en la necesidad de preservar los derechos políticos, civiles y de justicia de todas las personas. En este tenor se incluye: salvaguardar la libertad, el derecho de asilo, el derecho a elecciones democráticas, el ejercicio de la libertad de expresión y la igualdad de hombres y mujeres.

A partir de la suscripción de la Declaración Universal de los Derechos Humanos de 1948 por parte de los países miembros, la Organización de la Naciones Unidas (ONU) llevó a cabo una serie de convenciones, pactos y protocolos con la intención de ampliar los derechos de las personas y buscar su cumplimiento. Entre éstos se encuentran la Convención Internacional sobre la Eliminación de todas las Formas de Discriminación Racial (1965), el Pacto Internacional de Derechos Económicos, Sociales y Culturales (1966), el Pacto Internacional de Derechos Civiles y Políticos (1966) y la Convención sobre la Eliminación de todas las Formas de Discriminación contra la Mujer (1979). Además, el 13 de mayo de 1968 en Teherán, Irán, se celebró la Primera Conferencia Internacional de Derechos Humanos para examinar los progresos logrados en los veinte años transcurridos desde la aprobación de la Declaración Universal de Derechos Humanos de 1948 y preparar un programa para el futuro. Entre otros asuntos, la Conferencia Internacional exhortó a todos los pueblos y gobiernos a consagrarse a los principios contenidos en la Declaración Universal de Derechos Humanos y redoblar sus esfuerzos para ofrecer a todos los seres humanos una vida libre y digna que les permitiera alcanzar un estado de bienestar físico, mental, social y espiritual.

Posteriormente, el 25 de junio de 1993, los representantes ante la ONU de 171 países adoptaron por consenso la Declaración y Programa de Acción de Viena de la Conferencia Mundial de Derechos Humanos; en ésta se presentó a la comunidad internacional un plan común para fortalecer la labor en pro de los derechos humanos en todo el mundo. La conferencia, en su declaración y programa de acción, manifestó que los derechos a la educación, la capacitación y la información pública eran esenciales para promover y lograr relaciones estables y armoniosas entre las comunidades, así como para consolidar la comprensión mutua, la tolerancia y la paz.

La Conferencia Mundial de los Derechos Humanos de Viena amplió la perspectiva de los derechos humanos declarados en 1948. Entre los acuerdos novedosos se aprobaron acciones para:

Proscribir todas las manifestaciones xenofóbicas y otras formas de intolerancia; garantizar el derecho humano de los trabajadores migrantes y de sus familias; garantizar la igualdad de condición y los derechos humanos de la mujer; promover el respeto al derecho del niño, a su supervivencia y protección y el desarrollo de su participación; erradicar la práctica de la tortura; promover y fomentar la comprensión mutua, la tolerancia y la paz como parte de la educación en Derechos Humanos; promover y proteger los derechos de las personas pertenecientes a minorías nacionales étnicas, religiosas y lingüísticas; adoptar medidas tendientes a promover la democracia, el desarrollo y los derechos humanos. (Organización de las Naciones Unidas, 1993)

En el mes de marzo del año de 1995, en la ciudad de Copenhague, Dinamarca, se realizó la Cumbre Mundial Sobre Desarrollo Social. En su declaración, se evidencia que por primera vez se reconoce la importancia del desarrollo social y el bienestar de la humanidad. El compromiso adoptado por la comunidad internacional fue crear un entorno económico, político, social, cultural y jurídico que permitiera lograr el desarrollo social en los siguientes ámbitos:

1. Erradicar la pobreza en el mundo mediante una acción nacional enérgica a través de la cooperación internacional.

2. Promover el objetivo del pleno empleo como prioridad básica de las políticas económicas y sociales y preparar a todas las mujeres y hombres para conseguir medios de vida seguros 


\section{落 Sonta}

y sostenibles mediante el trabajo y el empleo productivos elegidos libremente.

3. Promover la integración social fomentando sociedades estables, seguras y justas, basadas en la promoción y protección de todos los derechos humanos, así como en la no discriminación, la tolerancia, el respeto de la diversidad, la igualdad de oportunidad, la solidaridad, la seguridad y la participación de todas las personas, incluidos los grupos y las personas desfavorecidos y vulnerables.

4. Promover el pleno respeto de la dignidad humana y lograr la igualdad y la equidad entre el hombre y la mujer y reconocer y aumentar la participación y la función directiva de la mujer en la vida política, civil, económica, social y cultural.

5. Promover y lograr los objetivos del acceso universal y equitativo a una educación de calidad, el nivel más alto posible de salud física y mental y el acceso de todas las personas a la atención primaria de la salud, procurando, de modo especial, rectificar las desigualdades relacionadas con la situación social, sin hacer distinción de raza, origen nacional, sexo, edad o discapacidad; respetar y promover culturas comunes y particulares; procurar fortalecer la función de la cultura en el desarrollo; preservar las bases esenciales de un desarrollo sostenible centrado en las personas y contribuir al pleno desarrollo de los recursos humanos y al desarrollo social.

6. Acelerar el desarrollo económico, social y humano de África y de los países menos adelantados.

7. Velar porque los programas de ajuste estructural que se acuerden incluyan objetivos de desarrollo social, en particular la erradicación de la pobreza, la generación de empleo pleno y productivo y la promoción de la integración social.

8. Aumentar sustancialmente o utilizar con mayor eficacia los recursos asignados al desarrollo social con objeto de alcanzar los objetivos de la Cumbre mediante la acción nacional y la cooperación regional e internacional.

19. Mejorar y fortalecer con espíritu de coparticipación el marco de la cooperación internacional, regional y subregional para el desarrollo social por medio de las Naciones Unidas y de otras instituciones multilaterales.

Para cumplir con los compromisos anteriores, la asamblea de la ONU resolvió establecer las siguientes políticas:

a. Un entorno propicio para el desarrollo social.

b. Erradicación de la pobreza.

c. Creación de empleo productivo y reducción del desempleo.

d. Integración social.

En la Cumbre Mundial sobre Desarrollo Social se hizo explícito que se recogían los compromisos de la Declaración de los Derechos Humanos de 1948 y que las propuestas y acciones tuvieron como guía, entre otras, la Declaración de la Conferencia Mundial de Derechos Humanos celebrada en Viena en el año de 1993.

Posterior a la Cumbre de Copenhague, en el vigésimo cuarto periodo extraordinario de sesiones, la Asamblea de la Organización de las Naciones Unidas, además de ratificar los acuerdos de la Cumbre realizada en Dinamarca y evaluar sus resultados, aprobó nuevas propuestas de iniciativas en pro del desarrollo social. ${ }^{1}$ En esta asamblea emergieron nuevos enfoques, tales como la exclusión, la inclusión, la cohesión social y la asistencia social.

\section{Definiciones conceptuales}

Una vez concluida esta sucinta recopilación de los acuerdos tomados por los países miembros de la Organización de las Naciones Unidas al interior de las cumbres, protocolos, conferencias y declaraciones realizadas en pos de mejorar las propuestas en torno de los derechos de las personas, nos abocamos a investigar sobre las definiciones conceptuales elaboradas acerca del Desarrollo Social.

En el documento Desarrollo Social, del Centro de Estudios Sociales y de Opinión Pública de la Cámara de Diputados del Congreso de la Unión de los Estados Unidos Mexicanos (2006), se señala que: 


\section{就 Sorvilo}

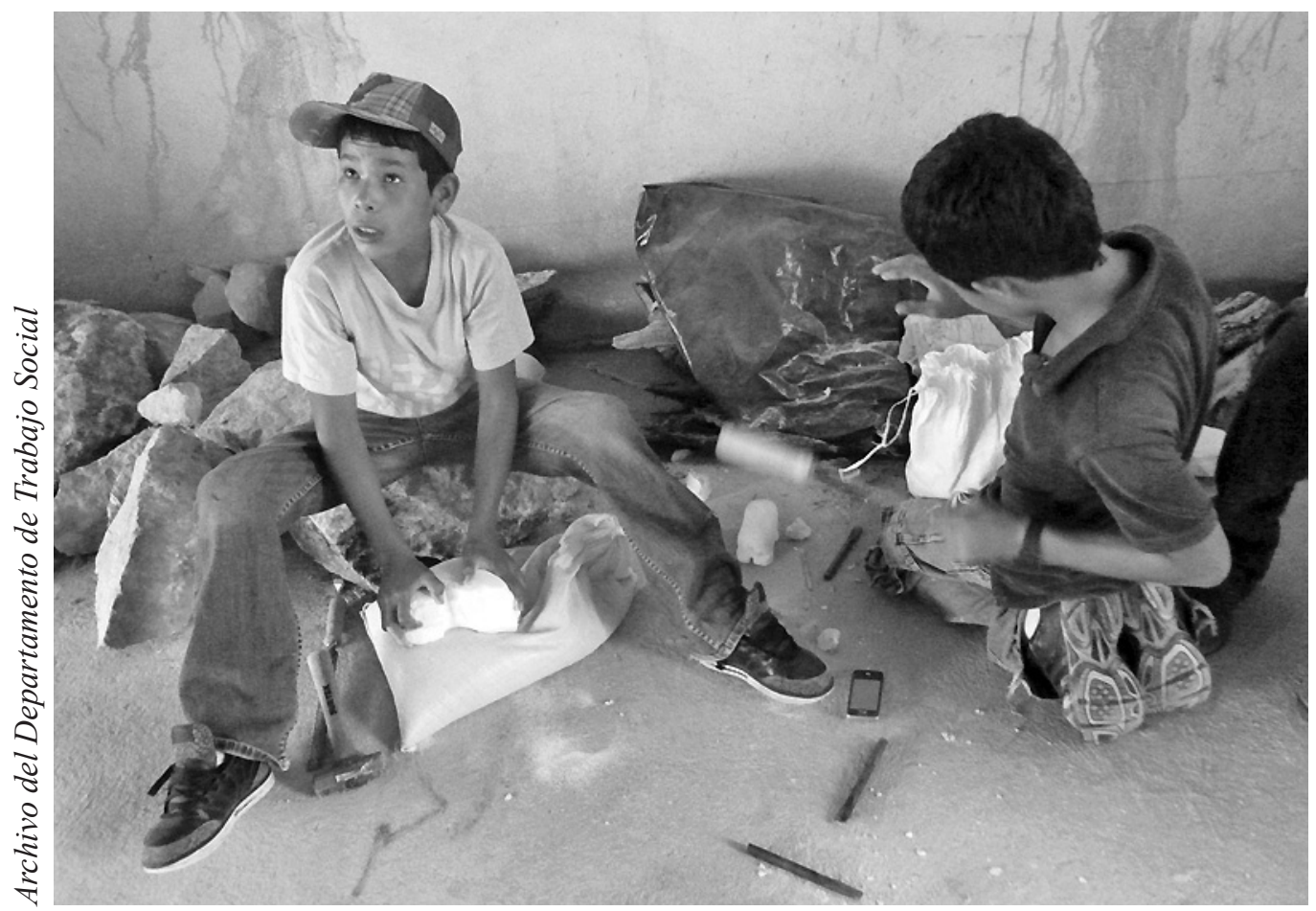

El desarrollo social es un proceso de promoción del bienestar de las personas en conjunción con un proceso dinámico de desarrollo económico, que, en el transcurso del tiempo, conduce al mejoramiento de las condiciones de vida de toda la población en diferentes ámbitos: salud, educación, nutrición, vivienda, vulnerabilidad, seguridad social, empleo, salarios, principalmente. Implica también la reducción de la pobreza y la desigualdad en el ingreso. En este proceso, es decisivo el papel del Estado como promotor y coordinador del mismo, con la activa participación de actores sociales, públicos y privados.

En el mismo documento, se indica que:

El enfoque de los derechos humanos se ha constituido en un referente de las políticas sociales, en particular los derechos humanos de segunda generación que se definen como los derechos económicos, sociales y culturales, debido a los cuales, el Estado de Derecho pasa a una etapa superior, es decir, a un Estado Social de Derecho". Entre los derechos sociales figuran la seguridad social, el trabajo, la formación de sindicatos, la educación primaria y secundaria gratuita, un nivel de vida que garantice la salud, la alimentación, el vestido, la vivienda, la asistencia médica y los servicios sociales necesarios.

Otro referente acerca de la definición del concepto la ubicamos en la Ley General de Desarrollo Social de México. En el artículo 1. ${ }^{\circ}$ se define como: "Garantizar el pleno ejercicio de los derechos sociales consagrados en la Constitución Política de los Estados Unidos Mexicanos, asegurando el acceso de toda la población al desarrollo social".

Por su parte, Rosalba Carrasco (1998: 4-13) considera que el Desarrollo Social es:

Un proceso de carácter integral que implica avanzar simultáneamente en los ámbitos del crecimiento económico, el bienestar social, la protección del medio ambiente y la consolidación de la democracia. Este exige la creación de instituciones democráticas, el respeto de todos los derechos humanos y libertades fundamentales; el aumento de oportunidades económicas equitativas, el respeto a la diversidad cultural, el derecho de las personas a 
pertenecer a minorías y la participación activa de la sociedad civil. El Desarrollo Social puede entenderse como un proceso dinámico centrado en los seres humanos, orientado al mejoramiento constante de las condiciones y la calidad de vida de la población y que requiere de un entorno económico y político favorable.

Por nuestra parte, y a manera de conclusión, consideramos que de las propuestas de la ONU es posible colegir la siguiente definición de Desarrollo Social:

Mejorar las condiciones de vida de la población y proporcionarle los medios de participar plenamente en las esferas económica, política y social. Adoptar medidas destinadas a afianzar la democracia y la transparencia en la toma de decisiones y a garantizar el imperio de la ley y la rendición de cuentas de las instituciones gubernamentales. Promover la potenciación de la mujer y la igualdad entre los géneros. Fomentar la paz y la seguridad y el respeto de todos los derechos humanos y libertades fundamentales, incluido el derecho al desarrollo, así como la tolerancia y el respeto a la diversidad cultural y étnica.

\section{Notas}

1 Resolución Nuevas iniciativas en pro del Desarrollo Social aprobada por la Asamblea General de la Organización de las Naciones Unidas en la Décima Sesión Plenaria del 1 de julio de 2000. Consultada el 5 de mayo de 2009. Disponible en: http://www.cinu.org.mx/temas/desarrollo/ dessocial/cumbre/cumbredessocial2000.

\section{Bibliografía}

Asamblea General de la Organización de las Naciones Unidas. (2000). Nuevas Iniciativas en pro del Desarrollo Social. Consultada el 30 de agosto de 2011. Disponible en: http://www.cinu. org.mx/temas/desarrollo/dessocial/cumbre/ cumbredessocial2000.pdf

Carrasco, R. (1998). Retos del desarrollo social en México. En Trabajo Social, 21. México: Escuela Nacional de Trabajo Social.
Centro de Estudios Sociales y de Opinión Pública. Desarrollo Social. (s.f.). Consultado el 30 de agosto 2011. Disponible en: http://archivos. diputados.gob.mx/Centros_Estudio/Cesop/ Eje_tematico/d_dsocial.htm\#_ftn1

Diario Oficial de la Federación. (2004). Ley General del Desarrollo Social. México. Consultada el 30 de agosto de 2011. Disponible en http://www. diputados.gob.mx/LeyesBiblio/pdf/264.pdf

Diario Oficial de la Federación. (2008). Programa Nacional de Derechos Humanos. Consultado el 30 de agosto de 2011. Disponible en: http://dof. gob.mx/nota_detalle.php? codigo $=5058383 \&$ fe cha $=29 / 08 / 2008$.

Organización de las Naciones Unidas. (1968). Proclamación de Teherán. Conferencia Internacional de Derechos Humanos. Consultada el 3 de septiembre de 2011. Disponible en: http:// www.tc.gob.pe/tratados/uni_ddhh/instru_alca gene2/teheran.pdfOrganización de las Naciones Unidas. (2000). Cumbre Mundial de Desarrollo Social. Consultada el 30 de agosto de 2011. Disponible en: http://www.un.org/documents/ ga/conf166/aconf166-9sp.htm

Organización de las Naciones Unidas. (2000). Nuevas Iniciativas en pro del Desarrollo Social. Consultada el 30 de agosto de 2011. Disponible en: http://www.cinu.org.mx/temas/desarrollo/ dessocial/cumbre/cumbredessocial2000.pdf

Organización de las Naciones Unidas. (s.f.). Conferencia Mundial de Derechos Humanos. Consultada el 30 de agosto de 2011. Disponible en: http://www. un.org/spanish/esa/devagenda/humanrights.html

Organización de las Naciones Unidas. (s.f.). Declaración Universal de Derechos Humanos. Consultada el 30 de agosto de 2011. Disponible en: http://www. un.org/es/documents/udhr/

Provencio, E. (2008). Seminario Enfoques del Desarrollo Social. Maestría en Políticas y Gestión del Desarrollo Social. Universidad de Sonora. Hermosillo, Son., 20-21 de marzo. 